\title{
Air Intake Prefilter Application at GT 13E2 PT. PJB UP Muara Tawar to Increase Plant Reliability, Availability, and Maintenance Time Interval
}

\author{
Komang Gede Nara Utama ${ }^{1}$, Muhammad Roshie Friansyah ${ }^{1}$, \\ Kevin Sanjoyo Gunawan ${ }^{2}$, Totok R. Biyanto ${ }^{2 *}$ \\ ${ }^{I}$ PT. PJB UP Muara Tawar, Muara Tawar, Indonesia \\ ${ }^{2}$ Engineering Physics Department, Institut Teknologi Sepuluh Nopember (ITS), Surabaya, Indonesia.
}

\begin{abstract}
The role of air intake filter in gas turbine is very important to produce clean air into combustion chamber. Combustion can perform perfectly in proportional rasio of fuel and oxygen.Filter air intake of gas turbine GT 13E2 use cylindrical cartridge filter type and it is installed vertically. air intake filter performance reduce rapidly if operated in dirty ambient air. This condition require filter replacement to maintain air mass flowrate that required in combustion. However, displacement cannot be performed while plant under operation. Therefore, the effort to increase life time of filter is necesary. Existing air intake filter in block 1 utilize 900 pieces of Donaldson brand. the specification of filter are 16 inches outside diameter. 34.5 inches height. celulose base with pourusity $52 \mu$. To reduce amount of attached particle in filter surface, installation weather louver is required. In order to increase plant reliability, availability and maintenance time interval of gas turbine, installation of prefilter and wheater louver at intake of compressor have been performed. This effort provide increasing plant reliability, availability and maintenance time interval. Finally, the benefit of this effort increase productivity of electricity and company profit.
\end{abstract}

Keywords: air, filter, prefilter, reliability, turbine

\section{Introduction}

Combined cycle power plant (CCPP) in Muara Tawar is industrial power plant using gas turbine. There are several components in gas turbine systems. One of the important component is combustion chamber. Combustion can perform perfectly in proportional rasio of fuel and oxigen. Clean air is requied as oxigen carrier medium. Hence, air filtering is important [1]. There are several filter types that used to filter combustion air in gas turbine[2]. Filter air intake of gas turbine GT 13E2 use cylindrical cartridge filter type and it is installed vertically. Material of cartridge filter is consist of combination of polyester fiber and selulose that have a capability retain particle with diameter more than 1 micron [3].

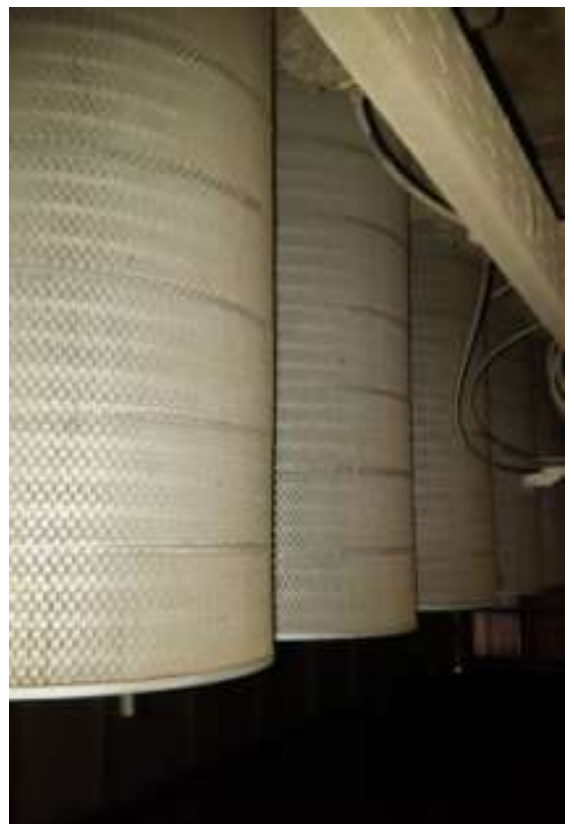

Figure 1. Filter Air Intake GT 13E2 
In actual, air intake filter performance reduce rapidly if operated in dirty ambient air. This condition require filter replacement to maintain air mass flowrate that required in combustion. However, displacement cannot be performed while plant under operation [4]. Therefore, the effort to increase life time of filter is necesary. One of the effort to overcome this problem is utilization of prefilter at the outside of existing filter. The other bennefit of this prefilter is easy to replace without disturbing operation of gas turbine.

\section{Theory}

Combustion air should be contaminant free to avoid slagging and fouling in filter and combustion chamber [5]. Components at air intake equipment consist of intake housing, doplet separator, cartridge filter dan silencer as shown in Fig.2.

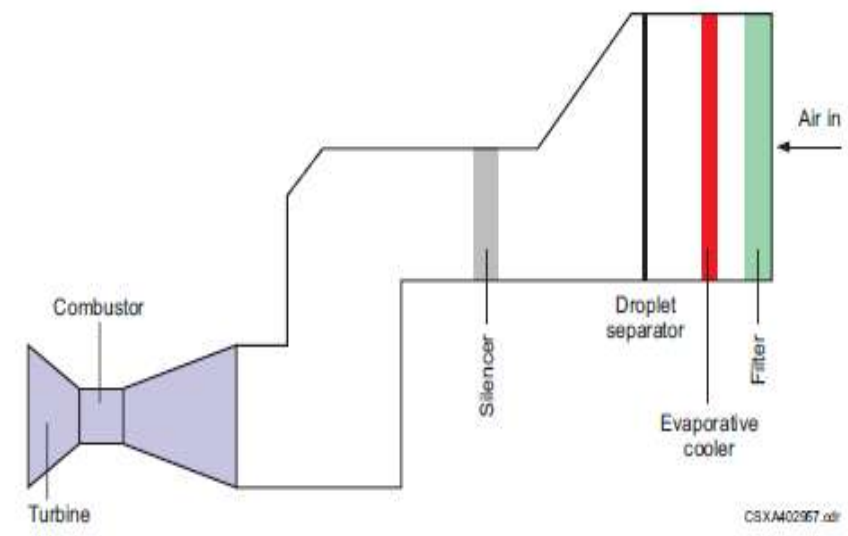

Figure 2. Air Intake Scheme

Gas turbine operating condition require huge of air to perform gas combustion. For example $22 \mathrm{MW}$ turbine requires inlet air 118,214 scfm. Howefer, in $1 \mathrm{ppm}$ particle in ambient air is equal to 5,8 $\mathrm{Kg}$ particle/day for gas turbine combustion air flowrate about $240747.8 \mathrm{Kg}$ /hour. Filtration is utilize to protect gas turbine from unwanted air contaminant. Although the utilization of air filter increase pressure drop and temperature, howefer the implementation of air filter has more benefit for overall systems [6]. Any air contaminant have possibility to reduce reliability, availability, and maintanant time interval [7]. The main purpose of inlet filtration is produce clean air to obtain proper operating condition and maintain turbine efficiency.

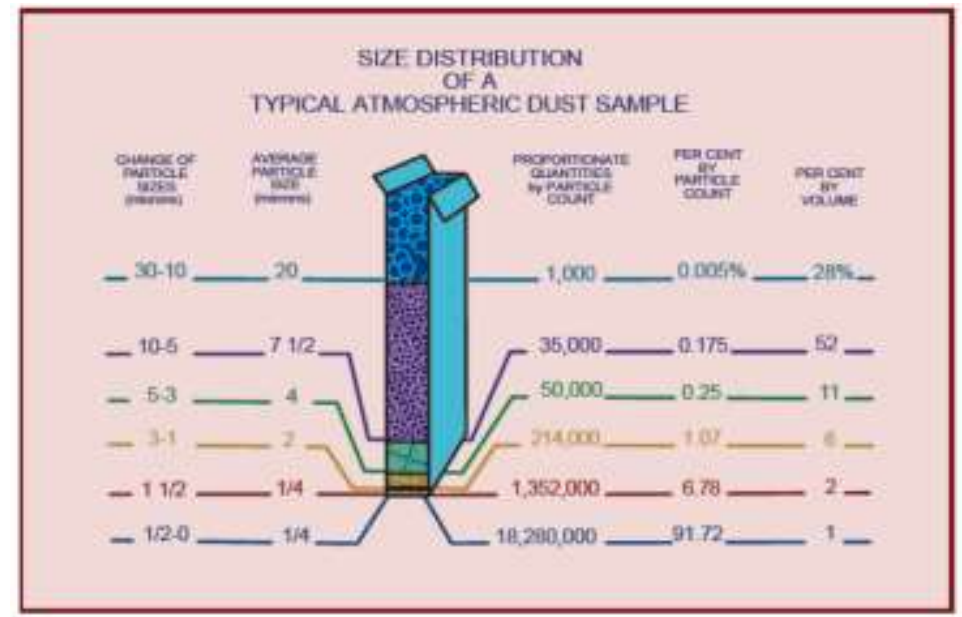

Figure 3. Size Distribution

\subsection{Problem Identification}

\section{Method}

Existing air intake filter in block 1 utilize 900 pieces of Donaldson brand. the specification of filter are 16 inches outside diameter. 34.5 inches height. celulose base with pourusity $52 \mu$. The detail specification is shown in Fig.4. 


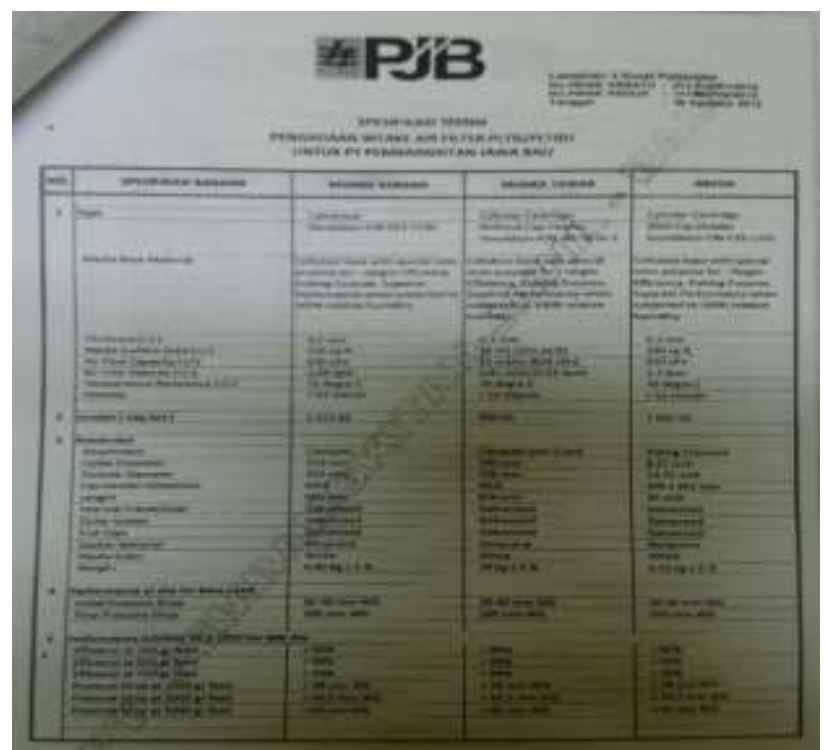

Figure 4. Filter Air Intake Specification

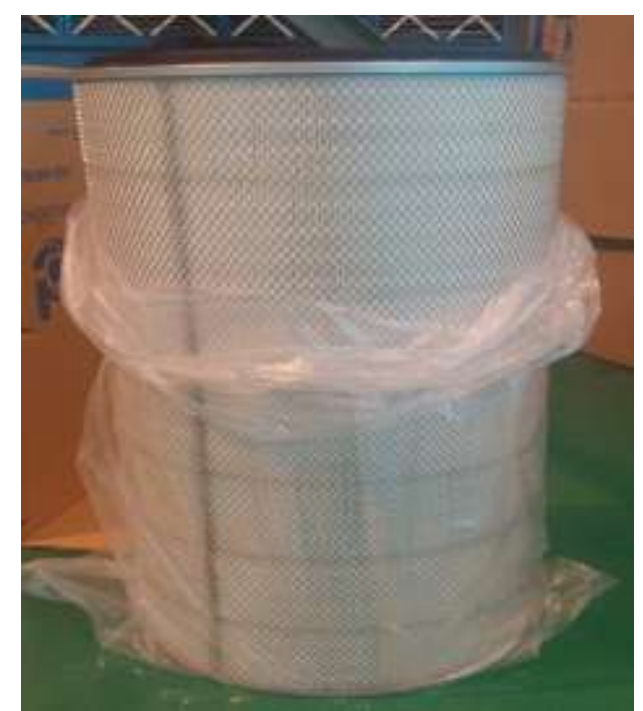

Figure 5. Filter Air Intake Donaldson

CCPP Muara Tawar environment located near beach that the air can be contaminated with small and medium particle such as dust, leaves and plastic. All contaminant with diameter more than $52 \mu$ will attach at filter surface and block the air into gas turbine. Level of filter pluging can be indicated from differential pressure between intake outlate filter. Fig 6 . is shown differential pressure indicator.

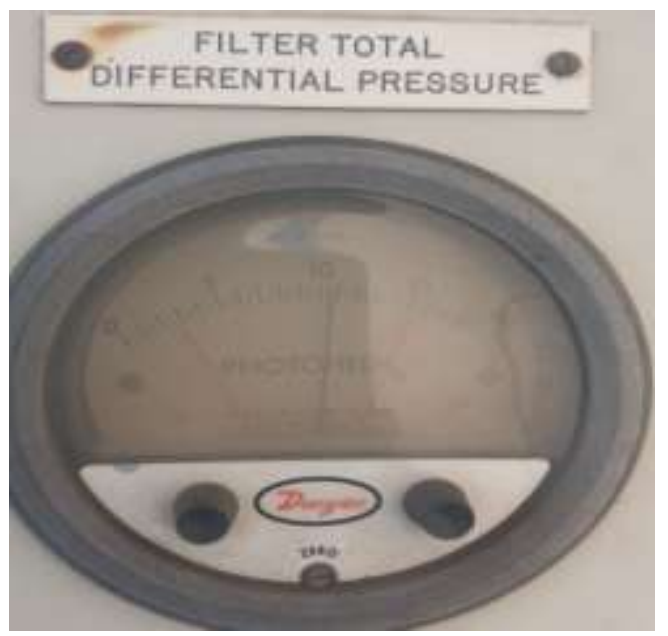

Figure 6. Dp Air Intake GT 1.2 Indicator 
Operating data was taken from date 1st march 2012 until 3rd march 2012. At 1st march 2012. 900 pieces of filter were replaced with new catridge and asume the filter under clean condition. Fig. 7 . shows the increasing pressure drop over the time versus electricity generation.

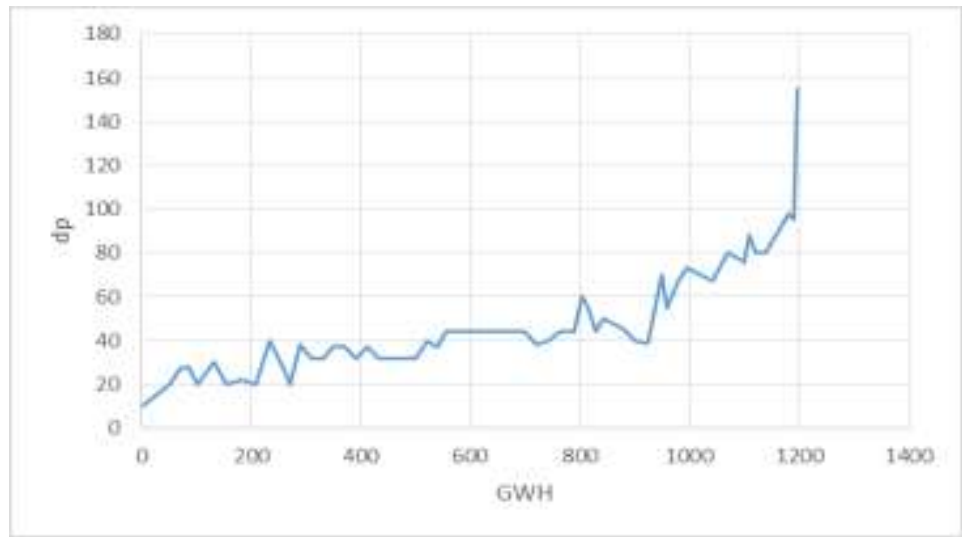

Figure 7. Dp Air Intake GT 1.2 Vs Production

\subsection{Improvement}

To reduce amount of attached particle in filter surface, installation weather louver is required.

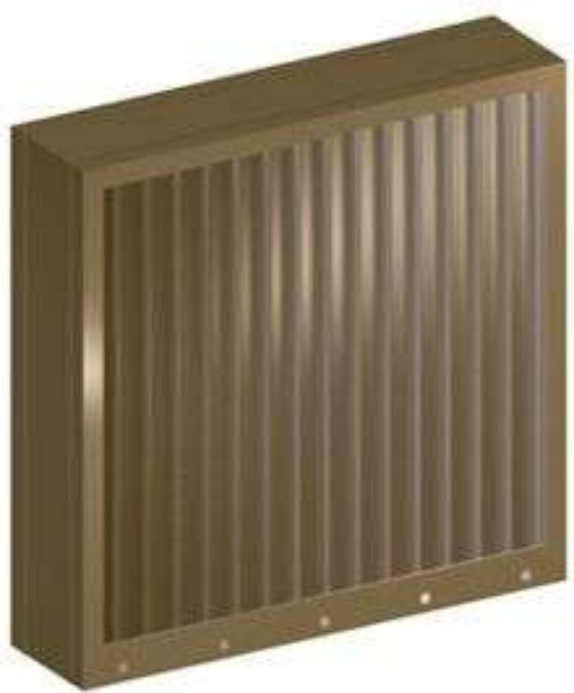

Figure 8. Weather Louver

To reduce small contaminant particle at surface filter, the utilization of prefilter with pourosity $>50 \mu$. Type of prefilter that used in air intake is GT 13E2 GT 12 is filter wraps G4 that can filtering $>10 \mu$.

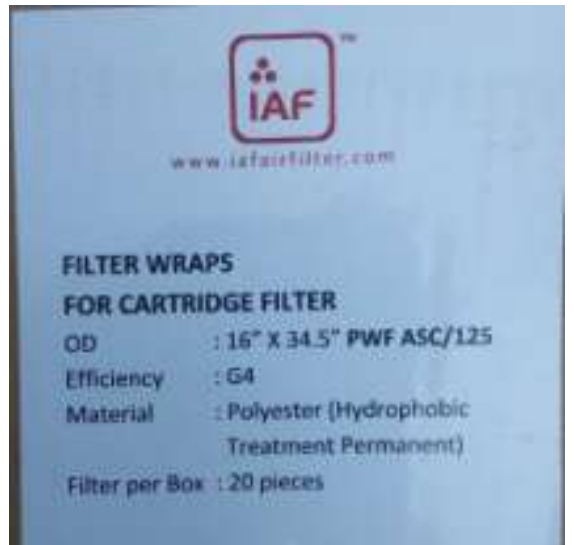

Figure 9. Prefilter Specification 

operation.

Prefilter installation can be done in plant under operation without disturbing overall power plant

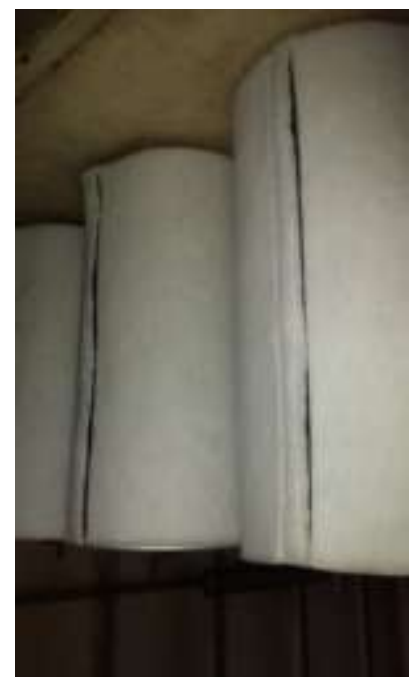

Figure 10. Prefilter in Filter Air Intake

\section{Discussion}

In order to increase plant reliability, availability and maintenance time interval of gas turbine, installation of prefilter and wheater louver at intake of compressor have been performed. Comparation before and after weather louver installation can be seen in Fig.11. which is the pressure drop reduce significantly.

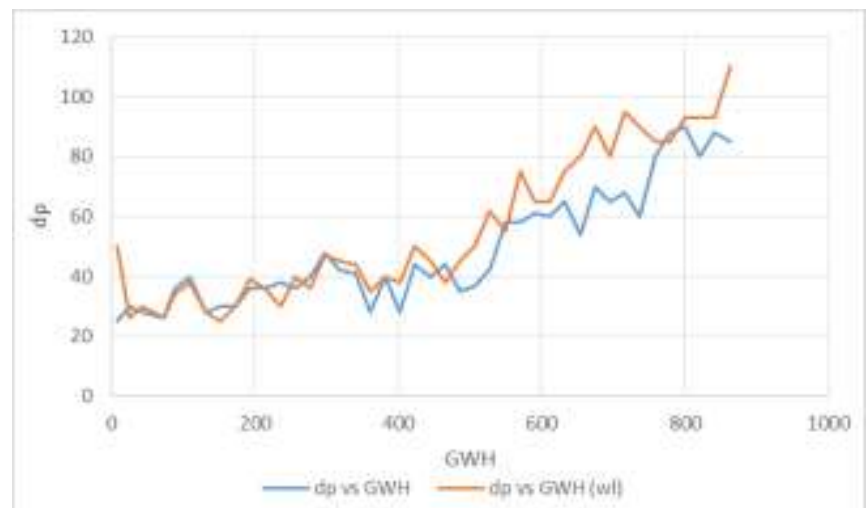

Figure 11. Dp Vs Gwh Before and After Used of Weather Louver

Figure 3.7 shows the pressure drop increment before and after prefilter installation.

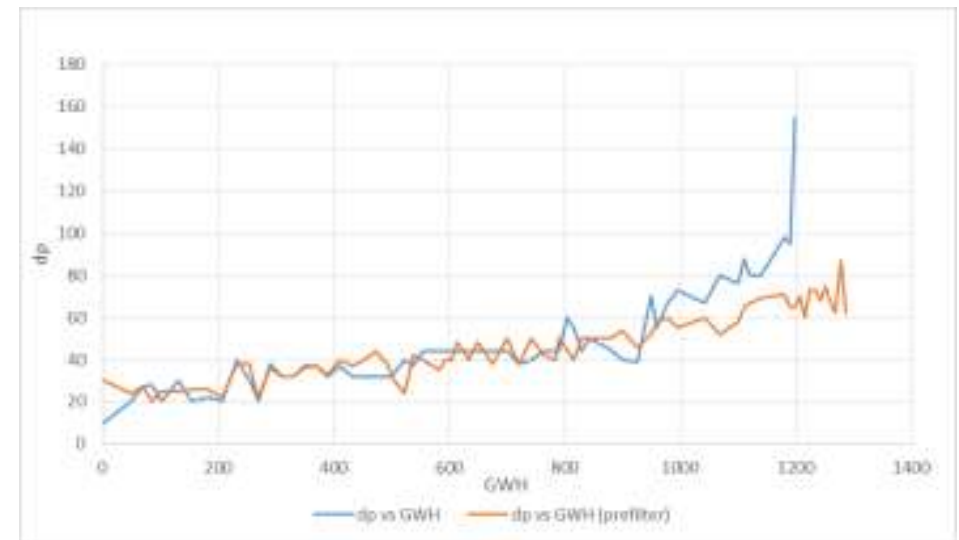

Figure 11. Dp Vs Gwh Before and After Used of Prefilter 


\section{Conclusion}

The installation of weather louver and prefilter have been performed and the pressure drop reduce significantly. This effort provide increasing plant reliability, availability and maintenance time interval. Finally, the benefit of this effort increase productivity of electricity and company profit.

\section{Acknowledgement}

The authors gratefully thank to PT. PJB UP Muara Tawar - Indonesia for providing the facilities in conducting this research.

\section{Reference}

[1]. $\quad$ O. S. Effiom, F. I. Abam and O. S. Ohunakin, "Performance modeling of industrial gas turbines with inlet air filtration system," Case Studies in Thermal Engineering, vol. 5, pp. 160-167, 2015.

[2]. M. Wilcox, M. Kurz and K. Brun, "Technology review of modern gas turbine inlet filtration systems,", International Journal Rotating Machinery, pp. 1-15, 2012.

[3]. D.I.N.EN-11822, "High-efficiency air filters - part 1: classification, performance testing, making," European Committee for Standardization, 2009.

[4]. M. Wilcox, A. Baldwin, A. Garcia-Hernandez and K. Brun, "Guideline for gas turbine inlet air filtration systems," in Proceedings of the Gas Machinery Research Council, 2010.

[5]. R. Kurz and K. Brun, "Degradation of gas turbine performance in natural gas service," Natural Gas Science Engineering, vol. 1, pp. 95-102, 2009.

[6]. "Inovative technologies for gas turbine air filtration," April $2013 . \quad$ [Online]. Available: 〈http://www.vokesair.com/system/uploads/industialplants_April_2013.pdf〉. [Accessed 14 June 2014].

[7]. H. Cohen, G. F. Roger and H. Saravanamuttoo, Gas Turbine Theory, 6th ed., England: Pearson Education Ltd., 2009. 